\title{
Electron Microscopic Studies of the Follicle Cells in the Thyroid Gland of the Dog
}

\author{
By

\begin{abstract}
Masaharu Tashiro and Shooichi Sugiyama
\end{abstract} \\ Department of Anatomy Nagoya University \\ School of Medicine, Nagoya, Japan \\ (Director: Prof. Dr. Shooichi Sugi yama)
}

The thyroid gland holds a unique situation among the endocrine glands. The follicle cells line the follicle cavity by their apical surface and have an intimate relation with the capillaries at their basal surface. Until recently, attention has been paid to the problem of function involved in this arrangement by light microscopy. Hormone substance secreted into the follicle cavity and stored here is held in readiness to be resorbed by the follicle cells and later transported basally to be discharged into the circulation. Today, interest in the process of secretion and transport has been aroused by repeated electron microscopic studies, and the present study was undertaken, using the thyroid glands of dogs, with the object of filling the gaps in knowledge and presenting some new evidence.

\section{Materials and Methods}

Forty dogs cunsisting of puppies shortly after birth and adults, one to three years old, were used and divided into two series, control and experimental. In the control series, 22 were sacrificed by a sharp blow at the base of the skull and exsanguinated via a thoracic incision. In the experimental series, 18 received single subcutaneous injections of two units ( 2 Meerschweincheneinheiten JunkmannSchoeller) per $100 \mathrm{~g}$ body weight of thyroid stimulating hormone (Pretiron Schering) and were sacrificed at intervals of one, two, three, 12 and 24 hours in the same manner as in the control series. Further, a puppy two weeks old was used for an additional experiment. It received a single injection of 200 units of the same hormone and was sacrificed after two hours.

The thyroid glands of the two series were removed immediately after sacrifice and divided into two halves. One half were cut into 
small pieces for electron microscopy, and the pieces were fixed in $\mathrm{P}$ a la de's fluid (1\% solution of osmic acid buffered with veronal acetate to $\mathrm{pH} 7.4)$. After the fixation, some of the pieces were dehydrated with ethanol, embedded in epoxy resin (Epon 812, Epon 815, DDSA) polymerized at $50^{\circ} \mathrm{C}$ under the influence of pyridine (Kushida, '59) or embedded in araldite by G l a uert's method, and the others embedded in methacrylate. Some were dehydrated with acetone and embedded in polyester resin polymerized at $55^{\circ} \mathrm{C}$ under the influence of benzoyle peroxide paste according to $\mathrm{K} \mathrm{u} \mathrm{s} \mathrm{h} \mathrm{i-}$ da's method ('60). Ultrathin sections were cut with glass knives by using a microtome model JUM 5 type. The sections were then stained for different hours (one, two, 4, 12 and 24 hours) with one of the following staining solutions: Those saturated with lead acetate, lead hydroxide and uranyl acetate, and 1\% potassium permanganate solution. The specimens were photographed at initial magnifications of 1000 to 7000 by using an electron microscope model JEM 5 G type and subsequently enlarged to the desired size. The other halves of the thyroid glands were also cut into pieces for routine histological observation. Some were fixed in Helly's or Ciaccio's fluid, and 6 to $8 \mu$ sections prepared were stained with hematoxylin and eosin or Heide $\mathrm{n} h$ a in's azan and with periodic acid-S $\mathrm{ch}$ if f's technique. Others were fixed in $\mathrm{K}$ ols ter's fluid, and 6 to $8 \mu \mathrm{sec}$ tions were stained with $\mathrm{H}$ e id e $\mathrm{n} h$ a in's iron hematoxylin.

\section{Observations}

Light Microscopy. The control series showed the following findings: Follicle cells were cubical and had round to oval nuclei. The chromatin reticulum was moderately dense. The nucleolus was relatively prominent. Preparations fixed in $\mathrm{Kol}$ ste r's fluid and stained with $\mathrm{He}$ ide $\mathrm{n}$ h a in's iron hematoxylin indicated that the follicle cells can be classified into two kinds, clear and dark follicle cells. The clear follicle cells contained a number of filamentous and rod-shaped mitochondria and sometimes a few colloid droplets and vacuoles. Some of the dark follicle cells corresponded to so-called La n gendorff's colloid cells. With periodic acid-Schiff's stain, the dark follicle cells were slender and stained intensely reddish purple. The experimental series showed that the follicle cells retain their original shape but are enlarged. The nuclei increased in size too. The cytoplasm contained numerous colloid droplets. Preparations fixed in Kolster's fluid and stained with $\mathrm{H}$ e ide $\mathrm{nha}$ i n's 
iron hematoxylin indicated that the follicle cells have abundant filamentous mitochondria, increase of vacuoles and numerous colloid droplets. The change was of short duration. They returned to a nearly normal appearance, with decrease in colloid droplets, within 12 to 24 hours after the injection.

Electron Microscopy. The control series showed the following results. In the apical surface of the follicle cells, a number of microvilli were found (figs. 1 and 4). Their lengths were 0.3 to 0.6 $\mu$ and their widths about $0.1 \mu$. Their matrix showed almost the same density as that seen in the apical cytoplasm. Very rarely, $\mathrm{Z}$ immermann's central flagellum projected from the apical cytoplasm into the colloid (fig. 4). The apical plasma membrane found between the microvilli rarely showed tiny indentations which have been often explained to be a sign of pinocytosis.

The intercellular space was limited by the lateral plasma membranes of adjacent follicle cells (figs. 1, 3 and 4). The space was almost the same from apex to basis of the follicle cell. Desmosomes were found here and there in this course and terminal bars at the apical margin. The space showed sometimes small dilations which have been considered as profiles of the intercellular canals that discharge the follicle colloid. The adjacent lateral plasma membranes formed sometimes relatively simple interdigitations.

The basal plasma membrane was smooth (fig. 3) and showed sometimes simple dilated infoldings. There were seen neither the phenomenon of pinocytosis nor small vesicles around the infoldings. The basement membrane was seen just outside this membrane. It was moderately electron dense and continued to that of the neighboring follicle cell. The narrow space between the basal plasma membrane and basement membrane was continuous with the intercellular space.

The nuclei were round to oval and limited by a double membrane consisting of the inner and outer membranes and a less dense layer in between (fig. 1). The outer membrane was unevenly studded with ribonucleoprotein particles and slightly ruffled. Their content was granular and far denser than the matrix of the cytoplasm and was somewhat much denser here and there at the periphery and center.

Immediately beneath the apical plasma membrane, a narrow zone free of ordinary cytoplasmic components was found and contained more or less numerous tiny vesicles (fig. 1). The vesicles were limited by a single smooth membrane and similar in appearance to the Golgi vesicles. The content was pale or slightly dense. 
This zone has been considered as a special zone by some authors (W issig, '60, - the superficial cytoplasmic zone; R oos, '60-Die apikale granulierte Zone). It was impossible to accurately follow their origin-whether they are derived by pinocytosis or from the $\mathrm{G}$ olg i complex. Although not found in ordinary sections, the zone contained a mesh of extremely fine fibrils in rare sections of the follicle cell with a central flagellum (fig. 4). The fibrils ran parallel to the apical plasma membrane (fig. 4).

In the deeper part of the follicle cell, mitochondria, endoplasmic reticulum and $\mathrm{Golg}$ i complex were found. The mitochondria were abundant especially in the basal half of the cell body and generally showed ovoid to rod-shaped profiles (figs. 1 and 3). They had a characteristic internal structure-cristae mitochondriales which were almost perpendicular to their long axis. They were limited by a double membrane consisting of the inner and outer membranes and a less dense intermediate layer. The inner membrane formed the cristae to which the intermediate layer continued.

The endoplasmic reticulum was well-developed, especially in the high cubical to columnar follicle cells. It consisted of irregularshaped vesicles and anastomosing cisternae and canals. They contained a homogeneous substance similar in density to the follicle colloid (figs. 1 and 3), and were regularly associated with ribonucleoprotein particles. The particles were specially well-formed in the part close to the mitochondria and absent or sparsely distributed in the part just close to the Golg i complex (fig. 1). The finding may suggest the existence of some intimate relation between the mitochondria and endoplasmic reticulum on one hand and the possibility of a continuity between the endoplasmic reticulum and the Golg $\mathrm{i}$ complex.

The Golgi complex was located generally in the supranuclear zone and consisted of a few pairs of smooth arcuated membranes arranged in layers, together with a number of vacuoles and also a considerable number of vesicles surrounding the first two (figs. 1 to 3). The vacuoles were about $0.5 \mu$ in size and the vesicles approximately $0.1 \mu$. Some of the vesicles were somewhat dense and similar in appearance to small secretory granules-transitions to secretory granules.

The secretory granules were limited by a distinct single smooth membrane and 0.2 to $0.5 \mu$ in size. They moved generally from the $\mathrm{G}$ o $\mathrm{lg}$ i complex towards the apical zone increasing in size and sometimes decreasing in density (fig. 1). Some reached near the basal 
plasma membrane but did not grow so much (fig. 3). From the observation of their distribution, size and frequency of occurrence, it became evident that they correspond to some of the colloid droplets found by light microscopy.

Paired centrioles were sometimes found in the supranuclear zone (fig. 1).

In the experimental series, the most characteristic features were as follows: The follicle cells became less electron dense. 1. Apocrinal cytoplasmic projections often appeared (figs. 5 and 7 ), especially near the terminal bars. They were round to oval, sometimes constricted at their base, and approximately $1.5 \mu$ in height and $1.3 \mu$ in width. They contained homogeneous material which was limited by a single smooth membrane and similar in density to or denser than the follicle colloid. Some fragments derived from them were found in the follicle cavity, but gradual smooth transitional forms from the apocrinal projections to the fragments were not demonstrated. 2. The tremendous dilation of the roughsurfaced endoplasmic reticulum began to appear already at the beginning stage of the experiment (figs. 5, 7, 8 and 9). The dilated endoplasmic reticulum extended over the entire area of the cell body, even into the apocrinal projections (fig. 7). They contained no special structures such as secretory granules and droplets, but a rather homogeneous material less than or as dense as the follicle colloid. The dilated endoplasmic reticulum enclosed a considerable number of mitochondria (figs. 6 and 8). The ribonucleoprotein particles associated showed no significant change but gave an impression of a slight decrease in number and somewhat uneven distribution in some follicle cells. As observed in the control series, the scarcity or absence of ribonucleoprotein of the endoplasmic reticulum, which was just close to the Golg i complex, was also confirmed (figs. 8 and 9). 3. An increase of secretory granules was found. The secretory granules were different in size and density and limited by a smooth single membrane. They were found numerously starting from the Golg i zone. The microvilli showed no significant change in size and number (figs. 8 and 9). The mitochondria showed no significant change, but the cristae mitochondriales were somewhat disturbed in arrangement (figs. 8 and 9). The intercellular space showed no frequent dilations. In a case of a puppy treated with 200 units of thyroid stimulating hormone, some follicle cells formed pseudopodium-like projections, which contained a big secretory granule or appeared as if they were isolating the 
follicle colloid (fig. 6).

\section{Discussion}

In an effort to elucidate the problem of the secretory process in the follicle cells, especially the site of the production of secretory granules, three possibilities have been considered. First, they may be derived from the rough-surfaced endoplasmic reticulum, second, from the Golg i complex, and third from the mitochondria. Earlier, Mon roe ('53, in rats and monkeys) and Braunste iner et al. (' 53 , in rats and guinea pigs) supposed that the rough-surfaced endoplasmic reticulum in the follicle cells may have important implications in the manufacture of protein hormone. De m p s y et al. ('55, in rats) suggested that the secretory product accumulates within the sacs of the endoplasmic reticulum, and as the product becomes denser, the sacs round up into the colloid droplets with ribonucleoprotein particles decreasing from their outer surface. Garnie r ('56, in rats) described that the intracellular colloid droplets probably correspond to the vacuoles which develop by dilation of the endoplasmic reticulum. W a $\mathrm{ng}$ ('58, in cats), $\mathrm{Fu}$ ji t a et al. ('58a and $\mathrm{b}$, in chicks), I rie ('60, in mammals) and $\mathrm{Sugaw}$ a $\mathrm{r}$ a et al. ('59, in man) expressed the same possibility. R o os ('60, in rats) suggested it to be the site of hormone synthesis (production of thyroglobulin) by observing that the content of this organelle is identical with the follicle colloid. Herman ('60, in salamanders) suggested two possibilities - that the cytoplasmic droplets or granules may possibly be derived from separated vesicles of the roughsurfaced endoplasmic reticulum and the other similar but smaller structures seen near or within the Golgi vesicles from this organelle. W is s i g ('60, in rats) considered that the homogeneous material contained in the endoplasmic reticulum represents merely a precursor of the secretory product, and that the droplets arise from the $\mathrm{G}$ olg $\mathrm{i}$ complex because of the marked similarity to the vesicles of this organelle. Harris o n et al. ('62, in seals) stated that secretion droplets of different size and density can be seen extending from the Golgi region towards the apex of the follicle cell.

The present results indicated in the control and experimental series that the secretory process starts in the Golg i complex (figs. 1, 2, 3 and 8). Here, small dense granules begin to appear and gradually move towards the apical cytoplasm growing in size. Some 
are directed towards the basal plasma membrane and almost reach it (fig. 3). This is partly in favor of the opinions of Bensle ('16, in opossums) and Bargmann ('39), who stated that the follicle cells secrete directly into the circulation while the follicle cavity functions as a storage space. Bra unsteiner et al. ('53, in rats and guinea pigs) stated that no evidence of direct hormone secretion into the circulation is observed. Le blo n d et al. ('48, in rats) denied direct secretion into the circulation by observing that radioiodine $\mathrm{I}^{131}$ was fixed in large amounts by stimulated thyroid glands soon after the injection.

Recent knowledge of the physiology of the thyroid hormone is summarized as follows (St a n bury, '55). Circulating inorganic iodide, which is yielded during digestion and absorption in the gastrointestinal tract, is trapped by the thyroid gland and enzymatically oxidized to iodine by the follicle cell. The iodine replaces hydrogen of the benzene nuclei of the tyrosil groups which are present in peptide linkage with the cell protein and produce diiodotyrosine in the oxidative step. The diiodotyrosine in turn undergoes oxidation and condenses to form thyroxine with extrusion of alanine. The thyroxine becomes peptide-linked after its formation and either enters the blood as thyroid hormone or is secreted into the follicle cavity to be stored as thyroglobulin. The thyroglobulin must be degraded to particles of smaller dimensions by proteolytic enzymes before entry into the blood as thyroid hormone. Histochemistry has indicated that intracellular colloid droplets resemble the follicle colloid in staining property and both have the same absorption maximum $(320 \mathrm{~mm})$ characteristic of thyroxine in ultraviolet absorption spectra of tissue sections (Gersh and Casperss o n, '40). Radioautography (L e b l o n d et al., '48, in rats) suggested that circulating iodide is bound to protein in the follicle cells (a prompt accumulation of protein-bound radioiodine in the apical zone) and thyroglobulin is deposited in the follicle colloid (after a longer interval the labeled iodine appears in the follicle cavity), and that excretion of thyroid hormone probably results from the proteolytic break-down of thyroglobulin in the colloid and the diffusion of the resulting fragments through the follicle wall. Another radioautography (Woll man et al., ' 55 , in mice) indicated that the proteinbound $I^{131}$ responsible for the radioautographic image always appears to be located in the colloid and suggested iodination of thyroglobulin to occur in the follicle colloid.

These results may help to a considerable degree explain the 
significance of the different cytoplasmic organelles in relation to synthesis, storage and release of thyroid hormone. It is supposed that material of proteins may be produced in the rough-surfaced endoplasmic reticulum of the basal half of the cell body and developed to thyroglobulin or peptide-linked thyroxine, as secretory granules in relation to the Golgi complex of the apical half. The possibility of a continuity between the endoplasmic reticulum and the Golg i complex may favor this concept (figs. 1, 8 and 9). In the rough-surfaced endoplasmic reticulum, the material may be supposed to be synthesized during the oxidative process by the help of the mitochondria. This relation can be understood from the well-known fact that the endoplasmic reticulum is considered as the site of protein synthesis and the enzyme of the mitocondria to be the site of oxidation (B r a c het, Biochemical Cytology, 1957). This relation is also shown by the close topographical relation between the mitochondria and the rough-surfaced endoplasmic reticulum in the present results (figs. 1, 8 and 9). An additional evidence of far more abundant distribution of ribonucleoprotein particles on some part of the endoplasmic reticulum, in close contact with the mitochondria, favors this concept (figs. 1, 8 and 9).

$\mathrm{Ek} \mathrm{hol} \mathrm{m}$ and $\mathrm{Sjöst} \mathrm{r}$ and ('57, in mice) divided the secretory granules into two kinds-one having a homogeneous, rather dense content and of regular round shape, and the other filled with a non-homogeneous material and their outline somewhat wavy. L e ve r ('60, in rats) found two types of granule, one corresponding to intracellular colloid bodies taking their origin likely from the endoplasmic reticulum and the other resembling in structure the siderosomes and lysosomes of liver cells. The present results showed that numerous granules of different density and size and sometimes non-homogeneous occur near or within the Gol gi complex (figs. 1, 2,3 and 4). These secretory granules may be supposed to be not different essentially but rather to change to some forms small enough to pass through the apical plasma membrane. The lesser dense granules may be of smaller molecular weight.

The morphological pattern of entry of secretory granules into the follicle cavity has to be examined by electron microscopy, but today has not been satisfactorily made. The above well-formed secretory granules are not observed to be extruded as such (fig. 1). Thus it has been said that the secretory granules lose their limiting membranes and are degraded to particles of smaller dimensions and diffuse through the apical plasma membrane. This observation 
is prevalent at present in the majority of the electron microscopic studies. The view that the secretory granules reach the apical plasma membrane together with their limiting membrane and finally the two fused membranes open to discharge the content has been also supported ( $\mathrm{Y}$ osh imura et al., '59, in chicks). From the recent observations of the triple layer system of the apical plasma membrane and microvilli ( $\mathrm{Ek} \mathrm{hol} \mathrm{m}$ and $\mathrm{S}$ jö s t $\mathrm{r}$ a $\mathrm{nd}$, '57, in mice), the difficulty of such a discharge may be supposed. No evidence accurate enough to confirm this was obtained in the present results. The authors would like to think that the apical plasma membrane and the superficial cytoplasmic zone may play an important role in the degradation, although $\mathrm{R}$ o os ('60, in rats) and $\mathrm{W}$ is s ig ('60, in rats) emphasized a similar significance upon the resorption of the colloid rather than upon the secretion.

The observations on apocrinal secretion have been often described, especially in the stimulated thyroid gland ( $\mathrm{Br}$ a u n te in e r et al., in rats and guinea pigs; $\mathrm{Fujita}$ et al., '58, in chicks; Yoshimura et al., '59, in chicks; Irie, '60, in a basedowian woman). $\mathrm{R}$ oos ('60, in rats) could not find such observations even in the series treated with thyroid stimulating hormone. In the present results, the apocrinal projections are often found in the experimental series and rarely in the control series. They contain homogeneous colloid-like material limited by a smooth membranea big granule and a very narrow cytoplasmic matrix are seen constricted at the base (fig. 6). Probably, the projections may be constricted off into the follicle cavity in a pattern similar to that found in the mammary gland ( $\mathrm{Bargmann}$ and $\mathrm{Kn} o \mathrm{op}$, '59 in rats).

The problem of the transfer of the follicle colloid from the follicle cavity into the circulation has been repeatedly discussed. Some insist on the possibility of the existence of intercellular canals to transport the follicle colloid ( $\mathrm{K}$ a $\mathrm{n} 0$, ' 52 , in man; Y o s h i m u ra et al., '59 ; Irie, '60, in mammals; $\mathrm{S}$ a w a $\mathrm{n}$ o et al., '59, in human fetuses). Occasional occurrence of dilations of the intercellular spaces found in the present study may correspond to some of these findings (figs. 5 and 6 ). In the dilations neither terminal bars nor desmosomes are found between adjacent follicle cell. Further, no direct evidence of channels connecting the follicle cavity and the interstitium is found. Only rarely some long dilations extending between the middle point of the lateral surface of the cell body and the basal plasma membrane is found. The long dilations may more effectively help the follicle cell function in taking up raw 
material for hormone synthesis and discharging hormone.

The pinocytotic phenomenon has been also discussed. Watari ('62, in snakes) found the frequent occurrence of pinocytotic vesicles near the apical and lateral plasma membranes and suggested the possibility of colloid release through the intercellular spaces and channels. W is sig ('60, in rats) found small vesicles and indentations of the apical plasma membrane, but could not determine their origin and fate. The problem still remains unsettled. P a la y ('58) explained that the follicle colloid is resorbed from the cavity by a process akin to pinocytosis and then is transported to the endoplasmic reticulum through which it passes to the base of the follicle cell for discharge into the circulation. B a r g ma n $\mathrm{n}$ ('62) expressed a similar view in his textbook. It is probable that the apical plasma membrane and the superficial cytoplasmic zone are also of significance in degradation to small molecular weight substance for release. W issig ('60, in rats) suggested a marked increase of small vesicles in this zone during accelerated colloid resorption. $\mathrm{R}$ oos ('60, in rats) also reported an increase in width of this zone during stimulation. However, the present results showed no significant difference in width and number of vesicles of this zone between the control and experimental series.

The most striking picture seen during stimulation in the experimental series was the dilation of the rough-surfaced endoplasmic reticulum and the increase of big faint secretory granules (figs. 7, 8 and 9 ). $\mathrm{R}$ oos ('60, in rats) reported that the endoplasmic reticulum becomes "bedeutend weitmaschiger" in the same experiment. Yoshimura et al. ('59, in chicks) dividing three stages in the same kind of experiment, found the occurrence of both big granules and big sacs of smooth-surfaced endoplasmic reticulum during the middle stage and suggested it to be a picture of resorptive activity. Ponse ('38) found in the thyroid gland stimulated with pituitary extract that the follicle cell take up the follicle colloid by forming pseudopodia projected into the follicle cavity. Williams ('38), from the observations on living follicles implanted in transparent chambers installed in rabbit's ears, arrived at the following conclusion on the mechanism of colloid release. At any given moment, at different points on the colloid borders, evaginations of follicle cells are produced and by so doing big colloid vacuoles are isolated into the follicle cells. The vacuoles migrate towards the base decreasing in size and finally disappear.

In the present results, some formations similar to evaginations 
and pseudopodia occurred in a puppy treated with 200 units of thyroid stimulating hormone and contained colloid within or appeared as if they isolated the colloid as a big droplet into the cell body after fusion (fig. 6). Ekholm ('60) demonstrated similar structures on the apical surface of the follicle cells of mice stimulated by thyroid stimulating hormone. W is sig ('60, in rats) also found them. It remains to determine what they are.

Microvilli have been considered to be related to resorptive activity (B ra un te in e r et al., '53, in rats; M o n roe, '53, in rats). The present results showed that they do not indicate accurate evidence of resorptive activity and that their presence may be rather significant as augmenting the effective surface of secretion and resorption.

\section{Summary}

The follicle cells of the thyroid gland of the dog were studied by electron microscopy, in combination with the effects of treatment with thyroid stimulating hormone, and the following results were obtained.

1. The follicle cells have a considerable number of microvilli extending from their apices into the colloid and rarely a central flagellum. 2. Just below the apical plasma membrane, the superficial cytoplasmic zone is found, free of secretory granules, mitochondria and rough-surfaced endoplasmic reticulum, and contain more or less numerous small membrane-bound vesicles. The vesicles remain in question whether they take their origin from pinocytosis or others. 3. The rough-surfaced endoplasmic reticulum is abundant, especially in the basal half of the cell body, usually dilated and contain a substance resembling follicle colloid. The ribonucleoprotein particles are well-formed especially in the part in close contact with the mitochondria, while they are absent or sparsely distributed in the part in contact with the Golgi complex. 4. The Gol $\mathrm{gi}$ complex lies in the supranuclear zone and consists of several paired membranes arranged in layers, a considerable number of small vesicles and a number of vacuoles. Some of the small vesicles resemble small secretory granules and suggest transitions to the latter. 5. Secretory granules are different in size and density, and move from the Golgi zone towards the apical zone. Some are directed towards the basal plasma membrane. Their further fate can not be followed. 6. The mitochondria show oval 
to rod-shaped profiles and are abundant, especially in the basal half of the cell body. The mitochondria show a close topographic relation to the rough-surfaced endoplasmic reticulum and are often completely enclosed by the latter. They contain well-formed cristae mitochondriales which are arranged perpendicularly to their long axis. 7. The nuclei show no special characteristics. 8. Treatment with thyroid stimulating hormone induces tremendous dilation of the rough-surfaced endoplasmic reticulum and increase of secretory granules, but no significant change in other organelles. 9. No relation between the process of colloid resorption and the organelles could be established morphologically. 10. The significances of the different organelles were discussed in relation to secretion and release.

\section{Literature cited}

B argma n n, W.: Die Schilddrüse. Handb. mikr. Anat., 2 T1, 1-136, Julius Springer Berlin, 1939.

- - Histologie und Mikroskopische Anatomie des Menschen. Sekretion u. Resorption. 84-91, 4. Aufl., Georg Thieme, Stuttgart, 1962.

$\mathrm{B}$ arg m a n n, W. and A. Kn o o p: Über die Morphologie der Milchsekretion. Lichtund elektronenmikroskopische Studien an der Milchdrüse der Ratte. Z. Zellforsch., $49:$ 344-388, 1959.

Bensley, R.R.: The normal mode of sacretion in the thyroid gland. Am. J. Anat., $19: 37-56,1916$.

Brachet, J.: Biochemical Cytology. Academic Press, New York, 1957.

Braunsteiner, H., K. Fellinger and F. Pakes ch: Electron microscopic observations on the thyroid. Endocrin., 53: 123-133, 1953.

Dem psey, E.W. and R.R. Peterson: Electron microscopic observations on the thyroid glands of normal, hypophysectomized, cold exposed and thiouraciltreated rats. Endocrin., $56:$ 46-58, 1955.

Ekhol m, R.: The ultrastructure of the stimulated thyroid gland. 4. Internationaler Kongress für Elektronenmikroskopie. Verh. Bd. 2, 378-381, 1960.

$\mathrm{Ekholm,} \mathrm{R.} \mathrm{and} \mathrm{F.S.} \mathrm{Sjöstrand:} \mathrm{The} \mathrm{ultrastructural} \mathrm{organization} \mathrm{of} \mathrm{the}$ mouse thyroid gland. J. Ultrastr. Res., 1/2, 178-199, 1957.

Fujita, H., M. Kano and S. Oka moto: Electron microscopic studies on the thyroidal colloid production. Arch. hist. Jap., 14:61-78, 1958a.

Fujita, H., M. Kano and T. Kido: Electron microscopic observations on the secretion of thyroid colloid into the follicular lumen. Arch. hist. Jap., 14: 567$574,1958 \mathrm{~b}$.

Garnier, B.: Beitrag zur Morphologie der pathologisch veränderten Schilddrüse im Elektronenmikroskop. Vergleich mit der normalen und der durch Propylthiouracil veränderten Rattenschilddrüse. Schweiz. Z. für Allg. Path. u. Bakt., 19: 129-149, 1956.

Ge"rsh, I. and T. Caspersson: Total protein and organic iodine in the colloid and cells of single follicles of the thyroid gland. Anat. Rec., 78: 303-319, 1940. 
H a r ris o n, R. J., I. W. R ow 1 and s, H. W. Whit ting and B. A. Y o ung: Growth and structure of the thyroid gland in the common seal (Phoca vitulina). J. Anat., $96: 3-15,1962$.

Herman, L.: An electron microscopic study of the salamander thyroid during hormonal stimulation. J. Biophysic. and Biochem. Cytol., $7: 143-150,1960$.

I $\mathrm{r}$ ie, M.: Electron microscopic observation on the various mammalian thyroid glands. Arch. hist. Jap., 19: 39-74, 1960.

Lever, J.D.: Observations on the fine particulate components in certain membranebound bodies of the rat thyroid cell. 4. Internationaler Kongress für Elektronenmikroskopie. Verh. Bd. 2, 381-384, 1960.

Mon roe, B. G.: Electron microscopy of the thyroid. Anat. Rec., 116:345-361, 1953.

Palay, S. L.: The morphology of secretion. Frontiers in Cytology. 305-342, Yale University Press, New Heaven, 1958.

Ponse, K.: Histophysiologie de l'activation thyroidienne. Rev. Suisse de Zool., 45 : 441-449, 1938.

Roos, B.: Die submikroskopische Struktur der Rattenschilddrüse. Ihre Beeinflussung durch hohe Dosen von thyreotropem Hormon. Ein Beitrag zum Studium der Sekretionsvorgänge in der Schilddrüse. Schweiz. Z. für Allg. Path. u. Bakt., 23: 129-157, 1960.

Saw ano, J. and T. Kan a y a : Electron microscopy of the thyroid in human fetuses. Acta anat. Nipp., 34: 45, 1959 (Abstract).

Stanbury, J.B.: Synthesis, storage and release of thyroid hormone. Werner's The Thyroid. 10-25, Hoeber-Harper Book, N. Y., 1955.

Sug a w a r a, Y., M. W a d a, K. Y a m a d a and S. Us ud a : Electron microscopic studies of human thyroid gland. J. Nagoya City Univ. Med. Ass., 10: 92-96, 1959.

W a n g, L.-S.: Studies on the fine structure of the thyroid gland and its secretory mechanism with electron microscope. Electron-Microscopy, 6: 184-191, 1958.

W a t a ri, N.: Electronenmikroskopische Untersuchungen über die Schilddrüse der Schlange (Natrix tigrina). Arch. hist. Jap., 23:21-51, 1956.

Willi a ms, R.G.: Microscopic studies of living thyroid follicles implanted in transparent chambers installed in the rabbit's ear. Am. J. Anat., 62: 1-31, 1938.

W issig, S. L.: The anatomy of secretion in the follicular cells of the thyroid gland. J. Biophysic. and Biochem. Cytol., $7:$ 419-432, 1960.

Wo $11 \mathrm{man}$, S. H. and I. Wodinsky: Localization of protein-bound I ${ }^{131}$ in the thyroid gland of the mouse. Endocrin., 56:9-20, 1955.

Yosh imura, F. and M. I r i e: Morphological basis to the mechanism of secretion and release within the thyroid gland cells. Clin. Endocrin. (Tokyo), 7: 367-394, 1959. 


\section{Explanation of plates}

Pieces of thyroid were uniformly fixed in $\mathrm{Pal}$ ad e's solution, embedded and stained $*$ in different ways.

\section{Key to Abbreviations used in Figures 1 to 9}

\author{
C : Centrioles \\ Ca: Follicle cavity \\ D : Desmosome \\ d : Dilation of the intercellular space \\ Er : Rough-surfaced endoplasmic reticulum \\ $g$ : Secretory granule \\ $\mathrm{G}$ : Golg i complex \\ I : Interdigitation
}

\author{
In : Indentation \\ M : Mitochondrion \\ mv : Microvilli \\ $\mathrm{N}$ : Nucleus \\ $\mathrm{n}$ : Nucleolus \\ $\mathrm{P}$ : Pseudopodium-like projection \\ $T$ : Terminal bar \\ $\mathrm{v}$ : small vesicle
}

1. A 5 months old male dog (control series). Terminal bars and microvilli are well-formed. The superficial cytoplasmic zone is devoid of secretory granules, mitochondria and rough-surfaced endoplasmic reticulum sacs, but rather contains small vesicles. Secretory granules are not extruded as such into the follicle cavity. The Gol g i complex consists of a number of vacuoles, paired membranes and a considerable number of small vesicles. Within this area, small and sometimes medium-sized electron dense vesicles, transitions to secretory granules, are contained. Mitochondria are seen relatively numerously, and most are completely or incompletely enclosed by rough-surfaced endoplasmic reticulum. Two centrioles are seen.

$\times 14,500$. * embedded in methacrylate.

2. A 15 days old male puppy (control series). Numerous secretory granules of different electron density and size are seen moving from the Gol g i zone towards the apical zone of the follicle cell. An apocrinal projection is seen containing a big faint granule. The matrix of some secretory granules is non-homogeneous. $\times 21,600$. * embedded in Araldite and stained with uranyl acetate solution.

3. A 15 days old male dog (control series). Some electron dense secretory granules are seen moving towards the apical plasma membrane and others towards the basal plasma membrane.

$\times 11,000$. * embedded in Araldite and stained with $\mathrm{KMnO}_{4}$ solution.

4. A 3 years old male dog (control series). A central flagellum projects towards the follicle cavity. In the superficial cytoplasmic zone, fine fibrillar structures, which are parallel to the apical plasma membrane, are seen.

$\times 32,000$. * embedded in Epon and stained with uranyl acetate solution.

5. A 16 days old male puppy (experimental series, 1 hours after the injection). An apocrinal projection is shown.

$\times 14,400$. * embedded in Rigolac and stained with $\mathrm{KMnO}_{4}$ solution.

6. A 14 days old male puppy receiving a single injection of 200 units of thyroid stimulating hormone. Pseudopodium-like projections are seen. An apocrinal projection is seen as if pseudopodium-like projections were fused to each other. $\times 7,500$. * embedded in Epon and stained with uranyl acetate solution. 
7. A 3 days old male puppy (experimental series, 18 hours after the injection). Sacs and cisternae of rough-surfaced endoplasmic reticulum are significantly dilated. $\times 7,500$. * embedded in Epon and stained with uranyl acetate solution.

8. A 2 days old male puppy (experimental series, 2 hours after the injection). The $\mathrm{Gol} \mathrm{g}$ i complex contains numerous vacuoles and vesicles. Some parts of cisternae and sacs of the rough-surfaced endoplasmic reticulum, which are close to the Golg i complex, are devoid of ribonucleoprotein particles. This suggests the possibility of connection of both organelles. A desmosome and an interdigitation are found. Two centrioles are seen.

$\times 29,400$. * embedded in Rigolac and stained with saturated lead hydroxide solution.

9. A 2 days old male puppy (experimental series, 2 hours after the injection). Two centrioles are seen. The Golg i complex consists of vacuoles, small vesicles and paired membranes. Some parts of the sacs and cisternae of the roughsurfaced endoplasmic reticulum are devoid of ribonucleoprotein particles. The possibility of connection of both organelles is shown. Abundant distribution of ribonucleoprotein particles on the outer surface of the endoplasmic reticulum, just near the mitochondria, is observed.

$\times 58,800$. * embedded in Rigolac and stained with lead acetate solution. 
Plate I

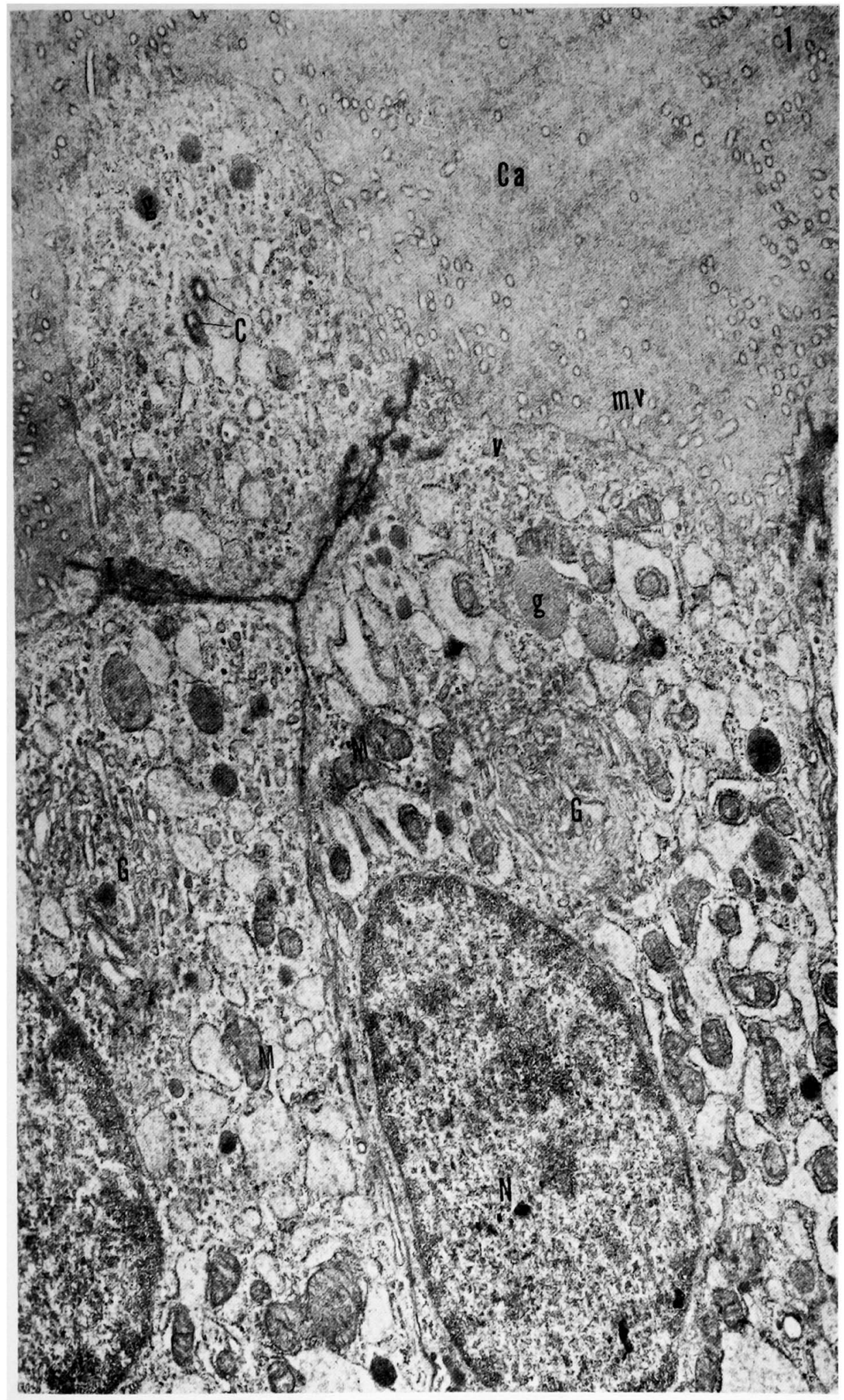

M. Tashiro and S. Sugiyama 
Plate II

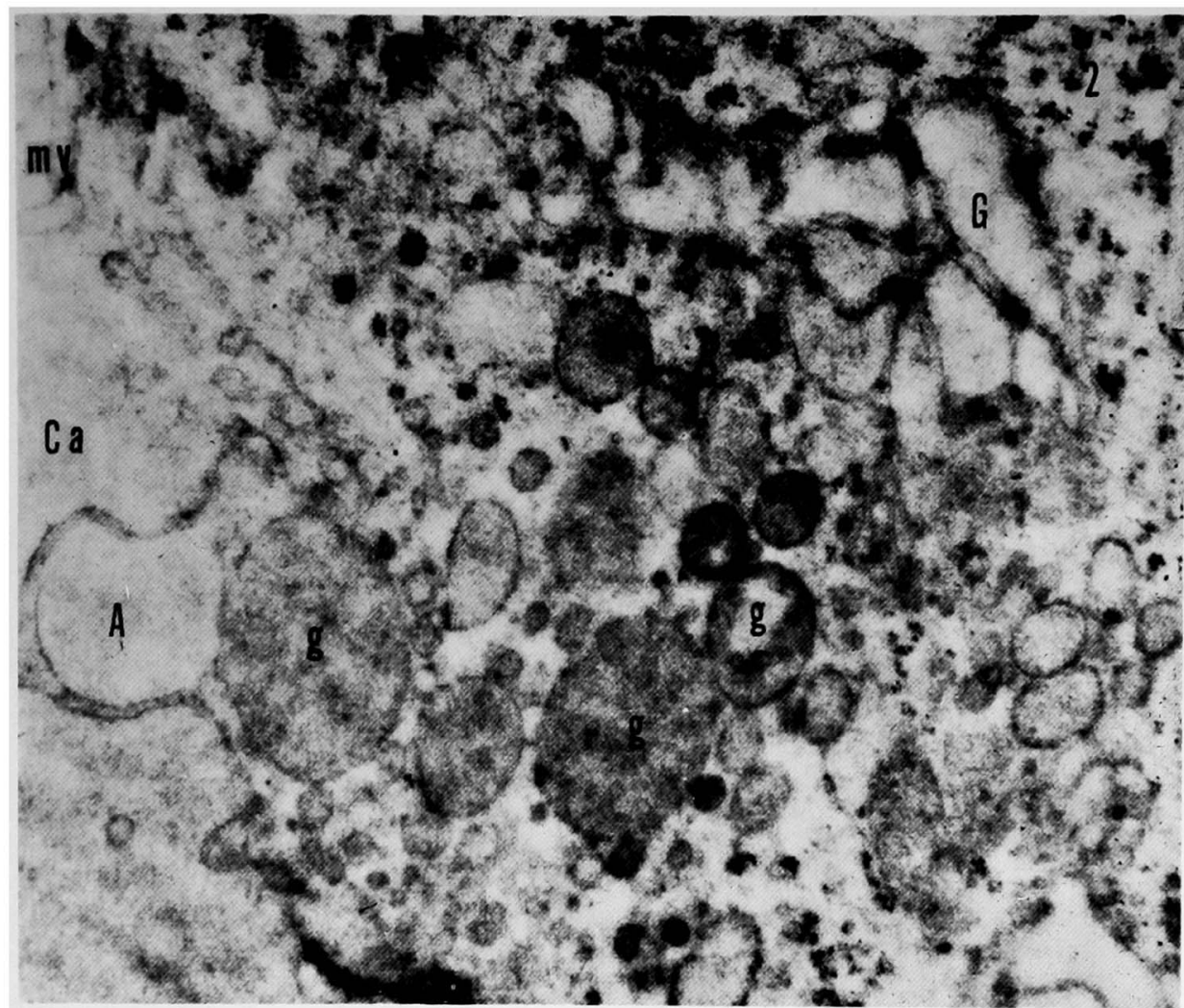

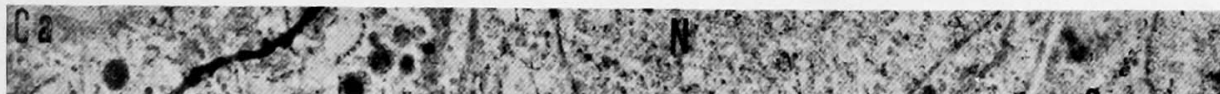

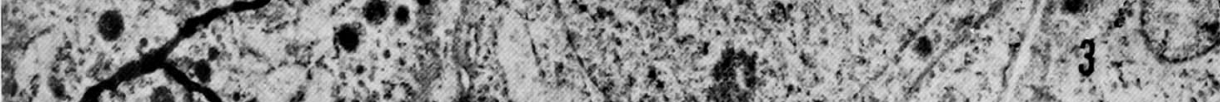



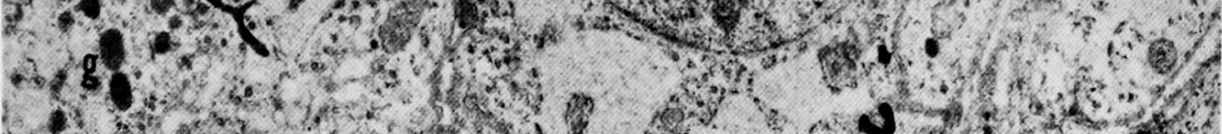

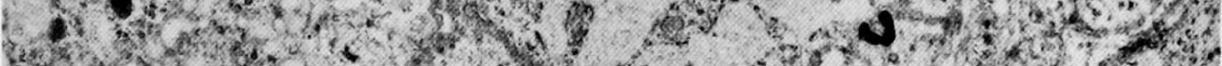

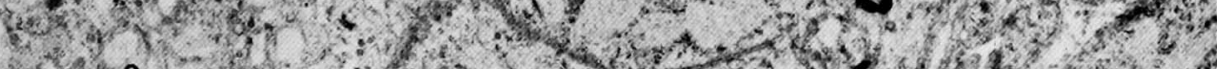

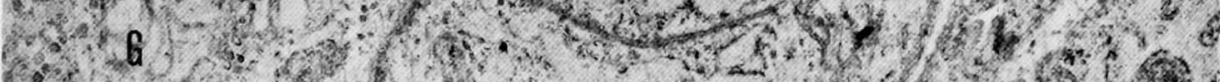

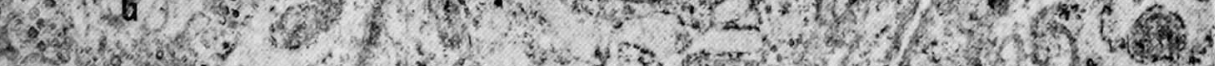

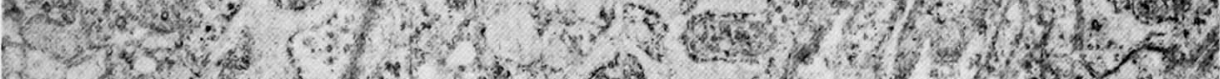

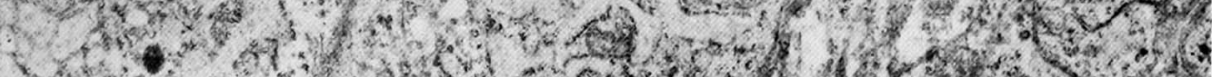

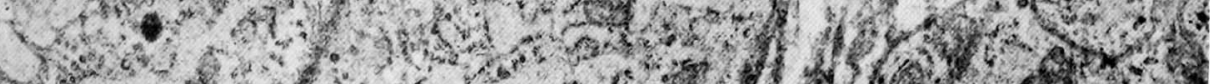

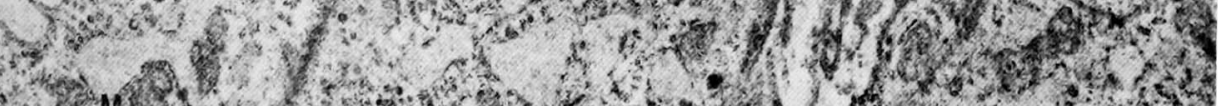

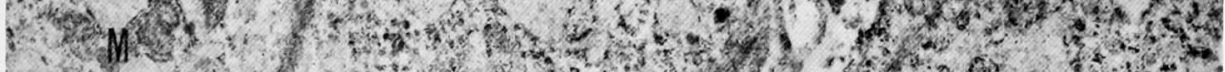

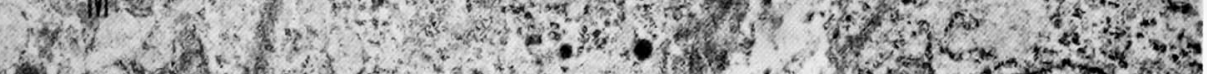

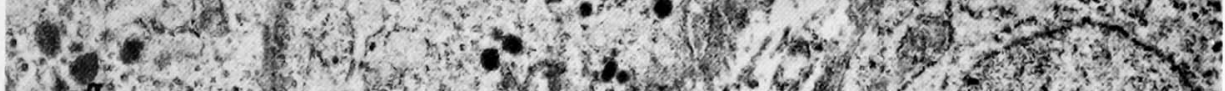



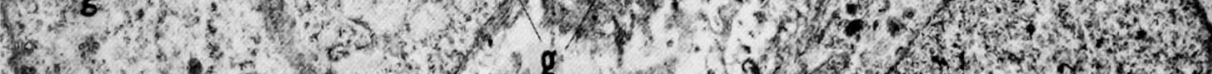

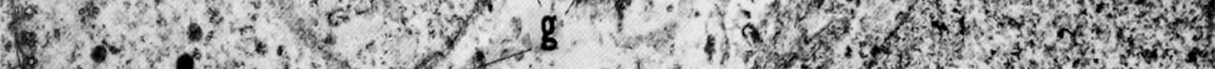

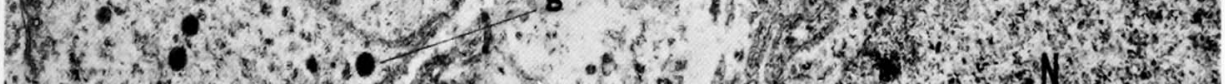
1.

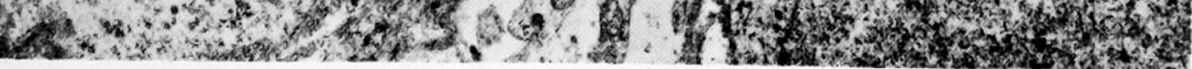



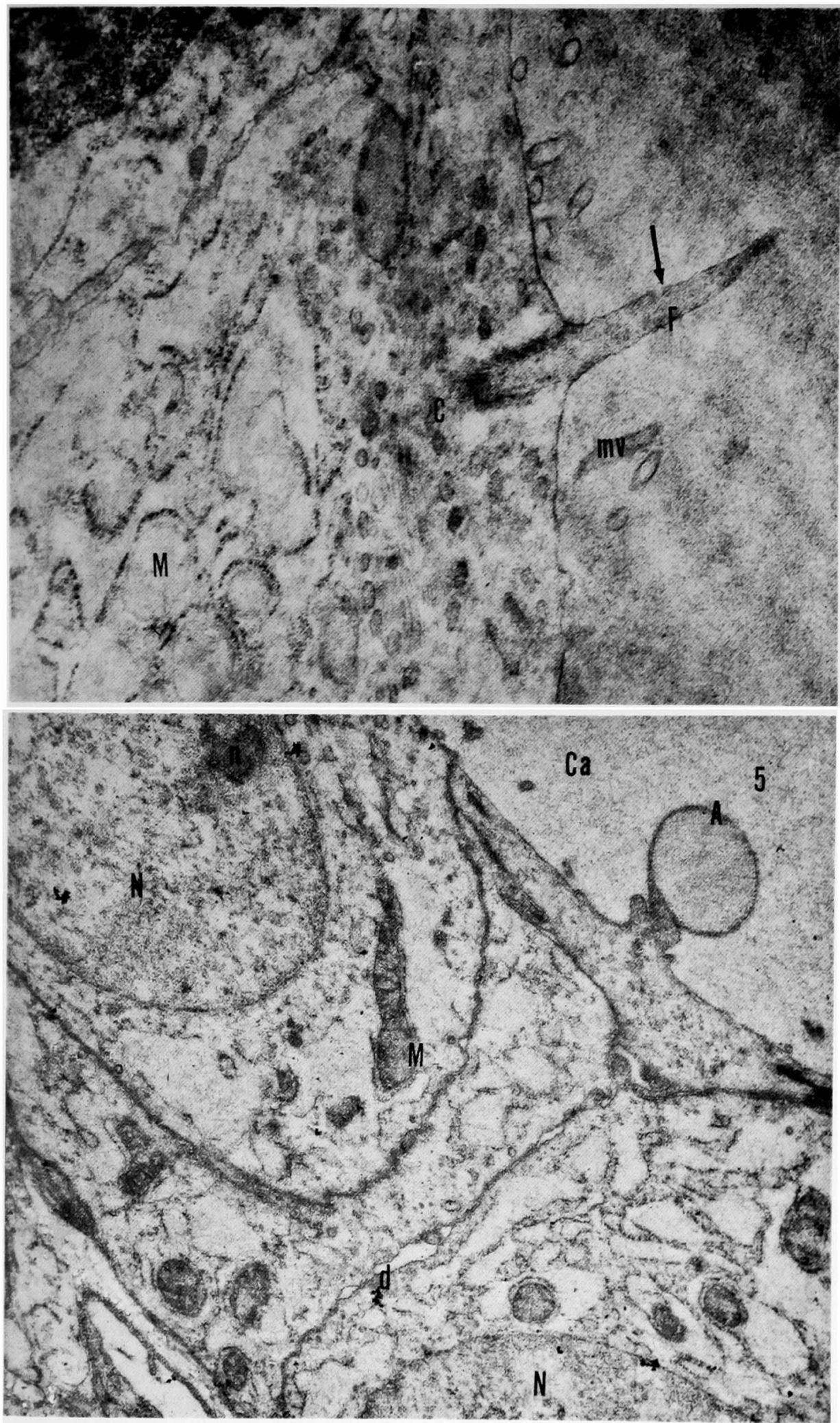
Plate IV

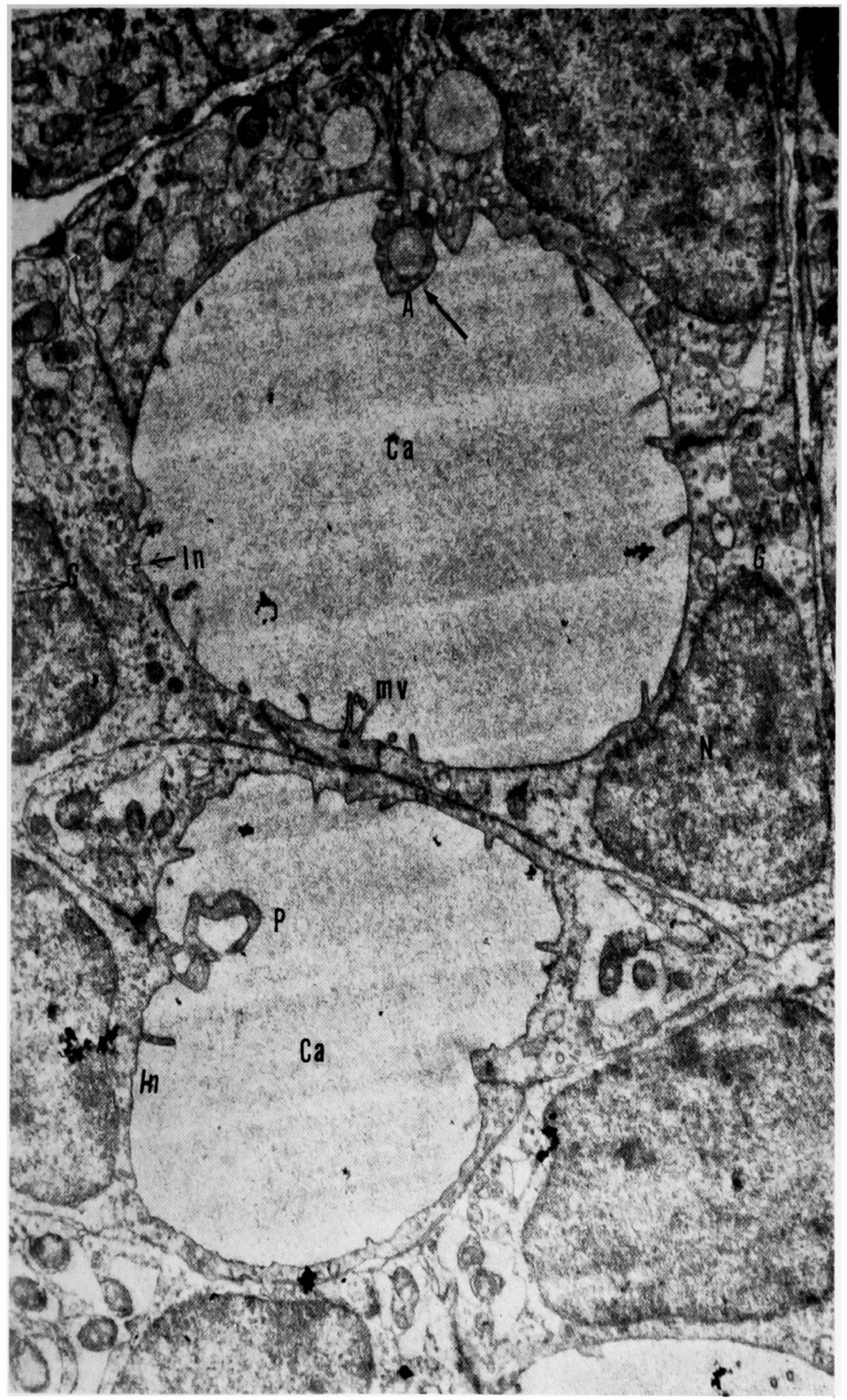

M. Tashiro and S. Sugiyama 


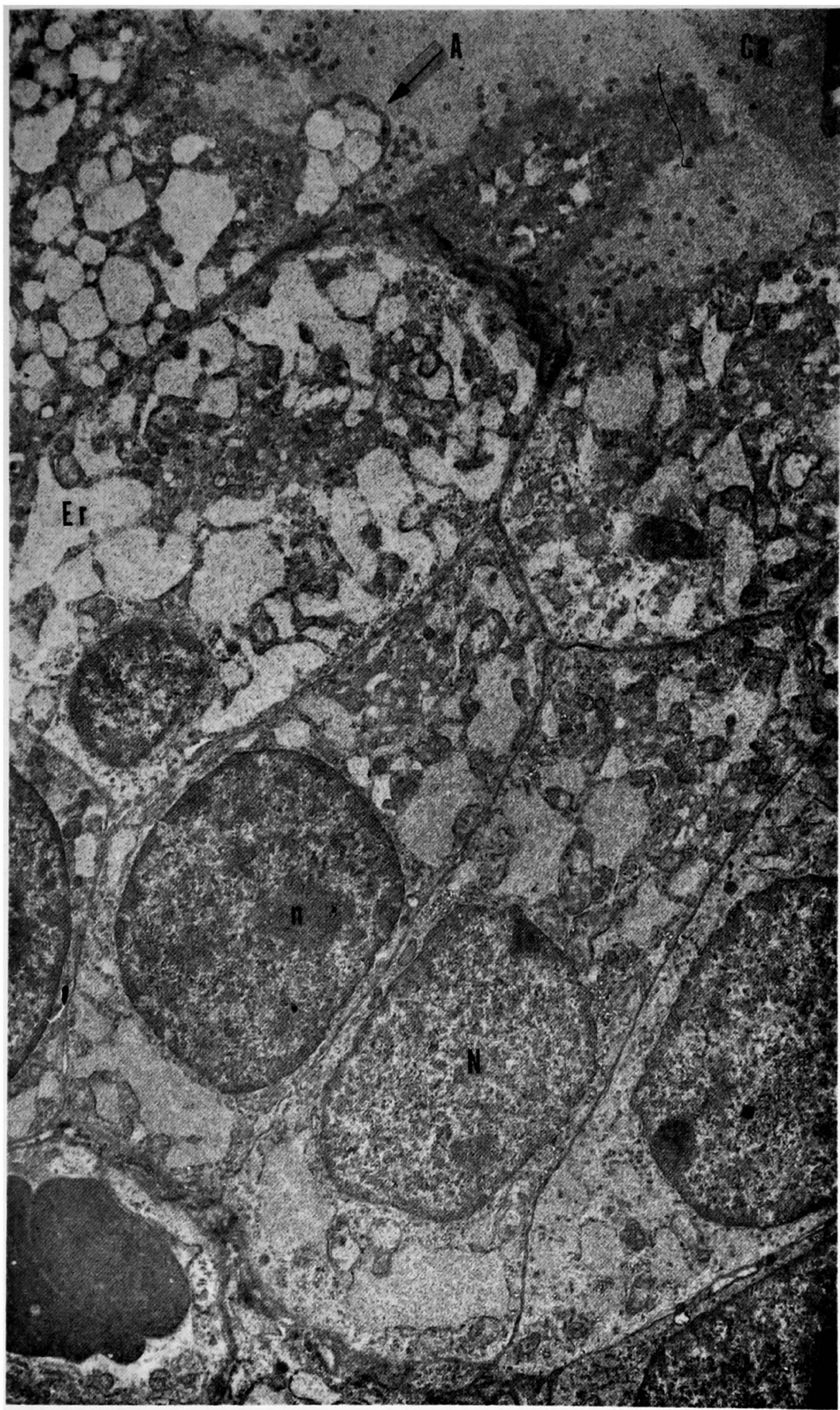

M. Tashiro and S. Sugiyama 


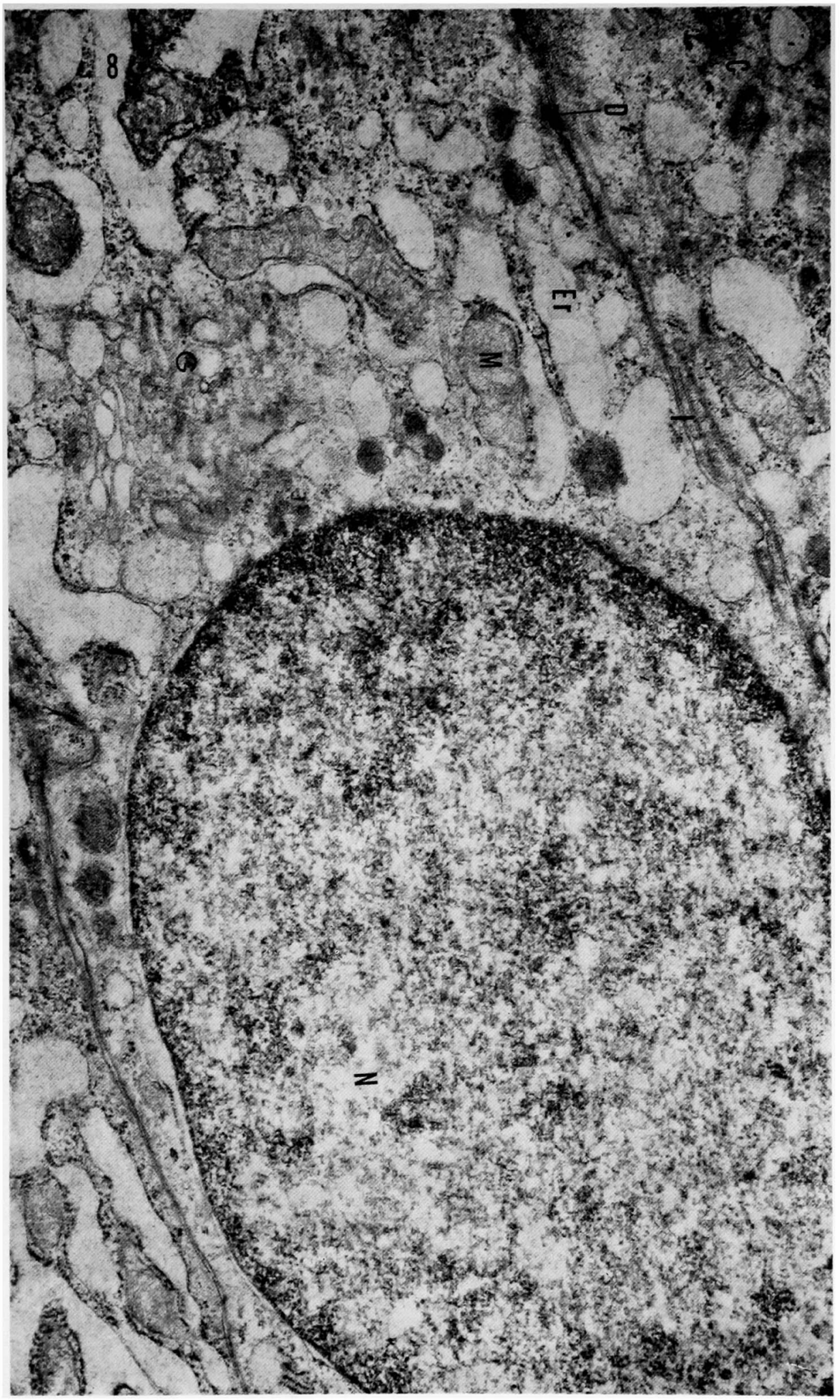

M. Tashiro and S. Sugiyama 


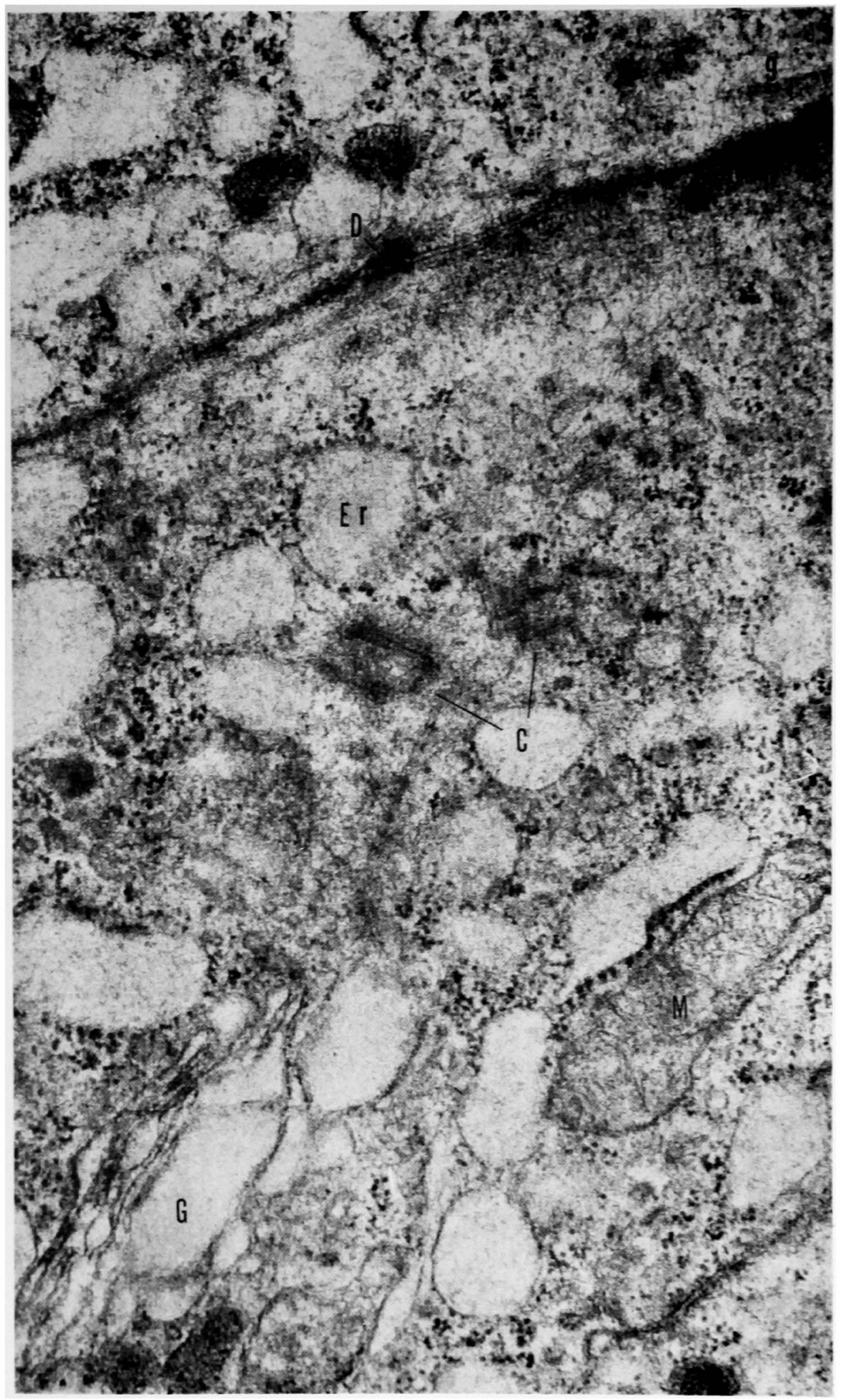

M. Tashiro and S. Sugiyama 